\title{
Hospitalized Children with Critical SARS-CoV-2 Infection Cared for in a Limited Resource Setting: Multicenter Cohort Study
}

Emmerson C.F. de Fariasa ( $\nabla$ emmersonfariasbrandynew@gmail.com )

Fundação Santa Casa de Misericórdia do Pará

Jefferson P. Piva

Universidade Federal do Rio Grande do Sul - UFRGS - Porto Alegre (RS)

Manoel J.C. Pavão Junior

Fundação Santa Casa de Misericórdia do Pará

Susan C.D. Sales

Fundação Santa Casa de Misericórdia do Pará

Luciana M.P. Nascimento

Fundação Santa Casa de Misericórdia do Pará

Dalila C.A. Pavão

Fundação Santa Casa de Misericórdia do Pará

Valeria T.S. dos Santos

Fundação Santa Casa de Misericórdia do Pará

Andressa H.O. Pinheiroa

Fundação Santa Casa de Misericórdia do Pará

Marília C.B. Alves

Fundação Santa Casa de Misericórdia do Pará

Mary L.F. M.F. Mello

Pronto Socorro Municipal Mário Pinotti's Hospital - HPSMMP - Belém

Patricia B. Carvalho

Fundação Santa Casa de Misericórdia do Pará

Maria C.A. Justino

Brazilian Ministry of Health

Gleice Clemente

Universidade Federal de Sao Paulo

Maria Teresa Terreri

Universidade Federal de Sao Paulo 
Keywords: COVID-19, coronavirus, MIS-C, multisystemic inflammatory syndrome, vaccination Posted Date: December 2nd, 2021

DOI: https://doi.org/10.21203/rs.3.rs-1044154/v1

License: (c) (1) This work is licensed under a Creative Commons Attribution 4.0 International License. Read Full License 


\section{Abstract}

Background: Some children can develop severe forms of SARS-CoV-2 infection either acutely or later, as represented by multisystemic inflammatory syndrome in children (MIS- C). To identify the risk factors for worse outcomes in hospitalized children and adolescents with severe acute SARS-CoV-2 infection and MIS-C.

Methods: This multicenter cohort study included all children and adolescents with confirmed or suspected critical SARS-CoV-2 infection admitted to the PICU between April 2020 and September 2021. The exclusion criteria were incomplete vaccinal status, immunocompromised status, and end-of-life decision. The main variables analyzed were epidemiological, clinical, and laboratory data, and ventilator settings at admission and after $72 \mathrm{~h}$. The patients were divided into three groups (G): confirmed coronavirus disease (COVID-19) with MIS-C criteria (G1), confirmed COVID-19 without MIS-C criteria (G2), and MIS-C criteria without confirmed COVID-19.

Results: The median age of the patients was 28 months in $\mathrm{G} 1$, with comorbidities in 40 patients $(72.7 \%)$ $(p<0.0001)$. The duration of exposure (median 23 days; $p=0.004)$ and fever were longer in $\mathrm{G} 1$ (12 days; $p=0.001)$. Moreover, invasive mechanical ventilation (IMV) was required in 44 patients $(80 \%, p<0.0001)$, and cardiogenic shock occurred in 26 patients $(54.2 \%, \mathrm{p}<0.0001)$ in $\mathrm{G} 1$. Subnutrition was most frequent in $\mathrm{G} 1$ in 55 cases $(57.3 \% ; p=0.01)$. Under nutrition ( $<2 \mathrm{SD}$ for weight), longer exposure time (odds ratio [OR]: $2.11 ; 95 \%$ confidence interval [Cl]: $1.37-3.25 ; p=0.001$ ), IMV time (OR: 2.6; 95\% Cl: 1.15-5.85; $p=$ 0.03 ), and length of hospital stay (OR: $10.94 ; 95 \% \mathrm{Cl}: 1.93-63.1 ; p=0.007)$ were associated with critical MIS-C in G1.

Conclusions: In the Brazilian Amazon area, specifically in the Pará state, we identified a cluster of more severe forms of pediatric acute or late SARS-CoV-2 infection.

\section{Introduction}

The coronavirus disease (COVID-19) outbreak has predominantly affected the adult population, while children present with relatively mild disease [1,2]. However, some children can develop severe forms of SARS-CoV-2 infection, either acutely or later, as represented by multisystem inflammatory syndrome in children (MIS-C); this is currently considered a rare COVID-19 postinfectious complication, a severe and newly emerging phenotype distinct from COVID-19 infection [3-5].

The aforementioned studies were mostly conducted in economically developed regions, and differences in the infrastructure of health services between these areas can result in distinct patterns of disease progression. Moreover, during the COVID-19 outbreak, some novel serotypes of SARS-CoV-2, causing different clinical scenarios and outcomes, have been identified globally [5-7]. Therefore, the risk factors for worse outcomes of COVID-19 forms in these studies may not be entirely applicable to other geographic regions or to less developed countries, which limits the extrapolation of the results. 
To date, there is limited information on the risk factors for pediatric critical COVID-19, acute infection and postinfection, and its outcomes, and only a few case series have been reported in resource-limited settings, such as the Amazon region [8]. The aim of this study was to identify risk factors for worse outcome associated with severe COVID-19 and MIS-C in hospitalized children in a limited care setting, such as the Eastern Brazilian Amazon region.

\section{Methods}

\section{Study design and participants}

Between April 2020 and September 2021, we conducted a multicenter prospective cohort study enrolling all children and adolescents with suspected or confirmed SARS-CoV-2 infection admitted to the pediatric intensive care unit (PICU) from three reference hospitals in the eastern Amazon area (Brazil): Fundação Santa Casa de Misericórdia do Pará (FSCMPA), Fundação Hospital das Clínicas Gaspar Viana (FHCGV), and Hospital e Pronto Socorro municipal Mário Pinotti (HPSMMP).

The study was approved by the institutional review board of the coordinating center (the other centers were co-participants). The parents or guardians of the children, or, when applicable, the children themselves, provided written informed consent before being included in the study.

The inclusion criteria were all children and adolescents (1 month to 21 years old) with suspected or confirmed severe SARS-CoV-2 infection or MIS-C who were admitted to the Pediatric intensive care unit (PICU). We excluded patients who were at end-of-life decision stages, immunocompromised patients, and those with unknown or incomplete vaccination status. Incomplete vaccination can lead to greater susceptibility to different agents and, therefore, a greater possibility of serious diseases, especially in children under 5 years of age. In cases of readmission in the PICU, only the first hospitalization was considered.

\section{Case definition}

The patients included in the study were divided into three [3] groups (G): G1 - patients with laboratorial evidence of current or previous SARS-CoV-2 infection who fulfilled the World Health Organization (WHO) MIS-C criteria, [9]; G2, patients with laboratorial evidence of current or previous SARS-CoV-2 infection, who did not fulfill the MIS-C criteria; and G3, patients who fulfilled MIS-C criteria without laboratorial evidence of current or previous SARS-CoV-2 infection, or who presented positive epidemiological background for COVID-19 infection but had a proven infection by other agents at admission (this subgroup will serve as a control for groups 1 and 2 regarding outcomes).

Laboratorial evidence of current and previous SARS-CoV-2 infection was based on having a positive reverse transcriptase polymerase chain reaction (RT-PCR) test result or a positive serological test (ELISA or immunochromatography), respectively. Suspected cases were considered as individuals with 
epidemiological links and clinical or radiological findings compatible with COVID-19, but the absence of molecular or serological tests, or whose results were inconclusive.

The presence of severe illness was determined by the presence of organ dysfunction requiring monitoring in the PICU, diagnosis of acute respiratory distress syndrome (ARDS), or respiratory failure, in addition to circulatory shock of any kind, encephalopathy, liver or gastrointestinal dysfunction, myocardial dysfunction or heart failure, coagulation disorders, and acute kidney injury [10]. Multiple organ dysfunction syndrome (MODS) was defined as the simultaneous occurrence of three or more organ dysfunctions, according to previously published criteria [11].

\section{Data collection}

Before beginning the survey, consultations with specialists were conducted, and educational lectures were given to the participants of the hospital teams. The researchers received prior training on data collection and were "blinded" to the research hypothesis. During the study, the coordinator and the assistant physicians from the units were responsible for validating the collected data and checking for suspicious errors, outliers, or missing values.

The patients included in the study were followed up prospectively from the date of hospital admission until discharge or death, whichever came first. Surviving patients and control subjects were censored on March 31, 2021. The main variables analyzed were epidemiological, clinical, laboratory, and radiological data, as well as ventilator settings at admission to the PICU and after $72 \mathrm{~h}$. All parameters were collected and processed at the participating medical centers, and all involved institutions used the same laboratory network for the requested analyses. All tests were performed according to the manufacturer's protocol.

The image exams and collection of biological samples were performed in the hospital care sector, according to the individualized clinical indications for each patient and the attending physicians' opinion.

Qualitative real-time RT-PCR assay for SARS-CoV-2 was performed in samples from nasopharyngeal swabs, sputum, or lower respiratory tract aspirates. Serological tests were performed using immunochromatography or ELISA methods, according to medical request; for qualitative serologies ( $\mathrm{lgG} / \mathrm{lgM})$, kits provided by the public Central Laboratory of the State of Pará (LACEN-PA) were used. A independent collaborating researcher reviewed the data. No genetic sequencing for SARS-CoV-2 was analyzed in this study; therefore, variants were not identified.

\section{Variable and short outcomes}

Baseline information (sex, age, weight, medical or surgical admission, definition of severe sepsis and septic shock, length of PICU stay, complex chronic condition [12], mortality and severity scores [13-15], and dates of admission and discharge), clinical manifestations, microbiological and laboratory findings, and outcome (death) were recorded using standardized data collection forms.

In addition to the epidemiological data, we evaluated the clinical course, associated diagnosis of MODS, ventilator settings, arterial blood gas analysis, the outcome, including the need and length of invasive 
mechanical ventilation (IMV), use of vasoactive drug infusion, weaning failures [16], progression to ventilator-associated pneumonia (VAP) [17], ventilator-free days over a 28-day period [18], development of ARDS [19] and death.

Nutritional status on admission was defined by the body mass index (BMI) Z-score using the most relevant growth standards and references. Z-scores were calculated using the World Health Organization AnthroPlus ${ }^{\circledR}$ software. Subjects were categorized as underweight (BMI Z-score < -2), normal weight (BMI Z-score $\geq-2$ and $\leq 1$ ), overweight (BMI Z-score $>1$ and $\leq 2$ ), or obese (BMI Z-score $>2$ ) [20].

The primary outcome was the occurrence of severe illness or deaths, while the secondary outcomes were in-hospital mortality at 28 days, length of oxygen supplementation, length of hospital and PICU stay, length of mechanical invasive support, and ventilator-free days at 28 days.

\section{Statistical analyses}

Considering that this research is an annual censoring study including all individuals with a diagnosis of COVID-19, no sample size was calculated. Descriptive statistics of continuous variables were reported as the mean and standard deviation (SD) for normally distributed data or median and interquartile range (IQR) for non-normally distributed data. Categorical variables are described as counts and percentages. Comparisons were assessed using the Kruskal-Wallis test (non-parametric distribution) or Welch's ANOVA (parametric distribution) for continuous variables and by $\chi^{2}$ test or Fisher's exact test for categorical variables. Adjustments were made for multiple comparisons. Variables with $p$-values $<0.05$ in the univariate analysis were included in a multivariate logistic regression model. The level of significance was set at a two-tailed $p$-value $<0.05$ with $95 \%$ confidence interval $(\mathrm{Cl})$. All statistical analyses were performed using IBM SPSS Statistics version 25.0.

\section{Results}

From April 2020 to September 2021, 528 children and adolescents with suspected or confirmed COVID-19 or MIS-C were admitted to three hospitals. Ultimately, 228 children who required intensive care support were selected for the study and were allocated into three groups (Figure 1).

The median age of the patients was 28 months in G1 (55 patients), 53 months in G2 (96 patients) and 33 months (77 patients) in G3.

The most used diagnostic method for SARS-CoV-2 infection was the serological test 193 (84.7\%), positive in $35(63.6 \%)$ in $\mathrm{G} 1$ and $58(60.4 \%)$ in G2. Shock syndrome Kawasaki disease (SSKD) was the most prevalent clinical form, present in $28(50.9 \%)$ patients from G1. The critical form of SARS-CoV-2 infection was present in 51 (92.7\%) patients from G1 and in 48 patients (50\%) from G2.

Male sex was more predominant in G1 than in G2 and G3 (45 [81.8\%] vs. 45 [46.9] vs. 31 [40.3]; $\mathrm{p}=$ $0.0001)$. Comorbidity was significantly more common in $\mathrm{G} 1$ (40 [72.7\%]; $p=0.01$ ). The median duration of exposure and fever were higher in the $\mathrm{G} 1$ than in $\mathrm{G} 2$ ( 23 days, $p=0.004$; and 12 days, $p=0.001$, 
respectively). According to nutritional assessment, the $\mathrm{G} 2$ present more patients classified as underweight $(57.3 \% ; p=0.01)$ (Table 1$)$.

The need for IMV and the duration of IMV were significantly higher in G1 than in G2 and G3 (44 [80\%], p < $0.0001 ; 5$ days, $p=0.001$, respectively). Severe ARDS was also significantly more frequent in $\mathrm{G} 1$ than in G2 and G3 (11 [20\%] vs. 9 [9.4\%] vs. 4 [5.2\%]; $p=0.003)$. Cardiogenic shock was predominant in $\mathrm{G} 1$ and G2, with $26(54.2 \%)$ and $16(41 \%)$ cases $(p<0.0001)$, respectively (Table 1$)$. The overall mortality of the sample was 63 deaths (27.6\%), with the highest mortality observed in G1 with 24 (43.6\%), $(p<0.0001)$ (Table 1).

Table 1. Epidemiological, clinical, intensive care support, therapeutic management and signs/symptoms of all included patients and groups 


\begin{tabular}{|c|c|c|c|c|c|}
\hline ıriables & $\begin{array}{l}\text { G1 } \\
(n=55)\end{array}$ & $\begin{array}{l}\text { G2 } \\
(n=96)\end{array}$ & $\begin{array}{l}\text { G3 } \\
(n=77)\end{array}$ & $\begin{array}{l}\text { All patients } \\
(n=228)\end{array}$ & $p$-value \\
\hline ale sex, $n(\%)$ & $45(81.8)$ & $45(46.9)$ & $31(40.3)$ & $121(53.1)$ & $<0.0001$ \\
\hline je (months), median (IQR) & $\begin{array}{l}28(9.2- \\
100.6)\end{array}$ & $\begin{array}{l}53(8.4- \\
90)\end{array}$ & $33(6-84)$ & $\begin{array}{l}34.7(6.03- \\
91.6)\end{array}$ & 0.545 \\
\hline inical admissions, n (\%) & $43(78.2)$ & $60(62.5)$ & $60(77.9)$ & $163(71.5)$ & $<0.1$ \\
\hline smorbidity, n (\%) & $40(72.7)$ & $60(62.5)$ & $45(58.4)$ & $145(63.6)$ & 0.01 \\
\hline xposure form: home, $\mathrm{n}(\%)$ & $47(85.5)$ & $76(79.2)$ & $0(0)$ & $123(32.3)$ & $<0.0001$ \\
\hline $\begin{array}{l}\text { rposure duration in days, median } \\
\text { QR) }\end{array}$ & $23(15-33)$ & $6(5-9)$ & $0(0)$ & $9(5-16)$ & 0.004 \\
\hline ver duration in days, median (IQR) & $12(9-15)$ & $4(2-6.75)$ & $\begin{array}{l}4.5(3- \\
7.15)\end{array}$ & $2.6(0-6.5)$ & 0.001 \\
\hline $\begin{array}{l}\text { utritional status: underweight, } n \\
\text { o) }\end{array}$ & $27(49.1)$ & $55(57.3)$ & $37(48.1)$ & $119(52.2)$ & 0.01 \\
\hline 'oductive cough, n (\%) & $44(80)$ & $65(67.7)$ & $45(58.4)$ & $154(67.5)$ & $<0.0001$ \\
\hline :vere dyspnea, n (\%) & $24(53.3)$ & $37(38.5)$ & $7(9.1)$ & $68(29.8)$ & $<0.0001$ \\
\hline rmphadenomegaly, n (\%) & $31(56.4)$ & $12(12.5)$ & $44(57.1)$ & $87(38.2)$ & $<0.0001$ \\
\hline astrointestinal symptoms*, n (\%) & $48(87.3)$ & $62(64.6)$ & $17(22.1)$ & $127(55.7)$ & $<0.0001$ \\
\hline Itaneous symptoms**, n (\%) & $49(89.1)$ & $30(31.3)$ & $34(44.2)$ & $113(49.6)$ & $<0.0001$ \\
\hline itaneous rash only, $\mathrm{n}(\%)$ & $47(85.5)$ & $23(24.0)$ & $34(44.2)$ & $104(45.6)$ & $<0.0001$ \\
\hline Leumonia at admission, $\mathrm{n}$ (\%) & $53(96.4)$ & $59(61.5)$ & $43(55.8)$ & $155(68)$ & $<0.0001$ \\
\hline se of oxygen, $\mathrm{n}(\%)$ & $55(100)$ & $77(80.2)$ & $77(100)$ & $209(91.7)$ & $<0.0001$ \\
\hline $\begin{array}{l}\text { sygen therapy time in days, median } \\
\text { २R) }\end{array}$ & $8(6-13)$ & $3(2-7)$ & $4(2-7)$ & $3(2-7)$ & 0.001 \\
\hline $\begin{array}{l}\text { vasive mechanical ventilation use, } n \\
\text { j) }\end{array}$ & $44(80)$ & $43(44.8)$ & $37(48.1)$ & $124(54.4)$ & $<0.0001$ \\
\hline TV in days, median (IQR) & $5(3-10)$ & $2(0-5.25)$ & $2(0-6)$ & $0(0-5)$ & 0.001 \\
\hline
\end{tabular}




\begin{tabular}{|c|c|c|c|c|c|}
\hline $\begin{array}{l}\text { intilator-free days at day } 28^{\text {th }} \\
\text { edian (IQR) }\end{array}$ & $0(0-1)$ & $1(0-2.75)$ & $1(0-3)$ & $0(0-2)$ & $<0.0001 / 1.0$ \\
\hline $\pm P, n(\%)$ & $13(23.6)$ & $10(10.4)$ & $4(5.2)$ & $\begin{array}{l}36(15.8) \\
27(11.8)\end{array}$ & $<0.0001$ \\
\hline ..PS, n (\%) & $33(60)$ & $32(33.3)$ & $25(32.5)$ & $90(39.5)$ & $<0.0001$ \\
\hline :vere ARDS, n (\%) & $11(20)$ & $9(9.4)$ & $4(5.2)$ & $24(10.5)$ & 0.003 \\
\hline isoactive drugs use, $\mathrm{n}$ (\%) & $45(81.8)$ & $39(40.6)$ & $73(94.8)$ & $157(68.9)$ & $<0.0001$ \\
\hline Irdiogenic shock, n (\%) & $26(54.2)$ & $\begin{array}{l}16(41.0) \\
16.6\end{array}$ & $5(6.5)$ & $47(20.6)$ & $<0.0001$ \\
\hline CU LOS in days, median (IQR) & $7(5-13.5)$ & $3(0-5)$ & $3(2-8.25)$ & $4(0-7)$ & $\begin{array}{l}<0.0001 /< \\
0.0001\end{array}$ \\
\hline गspital LOS days, median (IQR) & $14(10-20)$ & $\begin{array}{l}6.7(4.5- \\
11)\end{array}$ & $\begin{array}{l}15(10.5- \\
19.5)\end{array}$ & $9(6-15)$ & $\begin{array}{l}<0.0001 /< \\
0.9541\end{array}$ \\
\hline sath at 28 days, $n(\%)$ & $24(43.6)$ & $13(13.5)$ & $26(33.7)$ & $63(27.6)$ & $<0.0001$ \\
\hline
\end{tabular}

. *Diarrhea, nausea, vomiting, and abdominal pain; ** cutaneous rash, other mucosal lesions, oral manifestations. ARDS: Acute respiratory distress syndrome, VAP: Ventilator associated pneumonia, PICU: pediatric intensive care unit, LOS: Length of stay, IMV: Invasive mechanical ventilation, IQR: interquartile range.

G1 patients had a marked median increase in D-dimer levels at admission (G1: 1938.32 $\mathrm{ng} / \mathrm{dL} ; \mathrm{p}=$ $0.0014)$ and at day 3 (G1: $1275.41 \mathrm{ng} / \mathrm{dL} ; \mathrm{p}=0.047)$. The median CRP/albumin ratio was higher in $\mathrm{G} 1$ (day 1: 17.71; $\mathrm{p}<0.0001$ and day 3: 8.67; $\mathrm{p}=0.037$ ). Moderate hypoxemia on admission, assessed by OI, was more observed in G1 (median: 8.8; $\mathrm{p}<0.0001$ ) (Table 2).

Table 2. Laboratory, gasometry, and ventilator setting features of all included patients and groups 


\begin{tabular}{|ccccccc|}
\hline Variables & $\mathrm{G} 1$ & $\mathrm{G} 2$ & $\mathrm{G} 3$ & All & $p$-value*** & Reference \\
& $(\mathrm{n}=55)$ & $(\mathrm{n}=96)$ & $(\mathrm{n}=77)$ & patients $(\mathrm{n}$ & range \\
& & & $=228)$ & \\
\end{tabular}

Tidal volume $(\mathrm{ml} / \mathrm{kg})$

day $1 *$
$9.9(1.9)$
$7.7(2.5)$
$9.8(2.3)$
$8.1(2.68)$
$0.0001 / 0.001$

Peep $\left(\mathrm{cmH}_{2} \mathrm{O}\right)$ day $1 * *$
$8(7-10)$
7 (6-8)
7 (6-8)
$6(5-8)$
$0.0001 / 0.001$

Partial pressure of

carbon dioxide

35-45

$\left(\mathrm{pCO}_{2}\right)$, day $3^{*}$

$56.3(42.4) \quad 37.6(13.7) \quad 35.7(18.3) \quad 39.1(22.1) \quad 0.0064 / 0.013$

Hemoglobin day $1^{*}$

$\begin{array}{cccccc} & & & < & 12-18 \\ 9.98(1.36) & 11.7(1.8) & 16.7(1.74) & 11.2(1.84) & 0.0001 / 0.046 & \mathrm{~g} / \mathrm{dL}\end{array}$

Hemoglobin day $3^{*}$

$\begin{array}{cccccc} & & & < & 12-18 \\ 10.1(1.4) & 11.8(1.9) & 10.85(1.5) & 11.3(1.8) & 0.0001 / 0.034 & \mathrm{~g} / \mathrm{dL}\end{array}$

Lymphocytes day $1 * *$

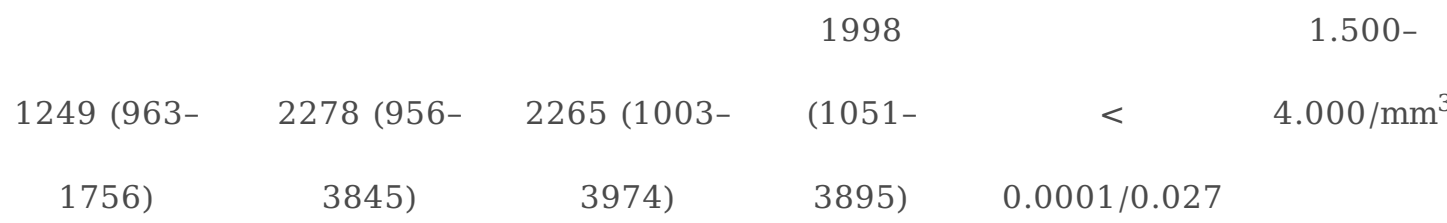

Prothrombin time day

$16(14.3-$

17.5)

Prothrombin time day

$3 * *$

D-Dimer day $1^{* *}$ $15.3(14.3-\quad 14.85(13.2-$

17.7) 17)

1938.32

(1084.9-

5008.5) $15.3(14.3-\quad 13.6(11.45-$

17.7)

21.5)

\section{9}

(12.9-

$<$

17.5)

$0.0001 / 0.043$

$15(13.8-\quad<0.0001 /<$

17.5)

769.84

(358-

1230) 


$\begin{array}{cc}< & <500 \\ 0.0001 / 0.0014 & \mathrm{ng} / \mathrm{dL}\end{array}$

D-Dimer Day 3**

$\begin{array}{cccccc}1275.41 & 853.81 & 527.54 & 490.92 & & \\ (605.51- & (417.35- & (478.46- & (261.72- & < & <500 \\ 3700) & 2851.29) & 707.75) & 830) & 0.0001 / 0.047 & \mathrm{ng} / \mathrm{dL}\end{array}$

International normalized

ratio day $3 * *$

$\begin{array}{ccccc}1.41(1.2- & 1.27(1.13- & 1.33(1.2- & (1.18- & < \\ 1.6) & 1.55) & 1.64) & 1.58) & 0.0001 / 0.004\end{array}$

\section{C-reactive protein day}

$1 * *$

$50.1(22.85-$

$3.81(1.41-$

$7.7(2.3-$

$\mathrm{mg} / \mathrm{dL}$
86.1)
$7.6(1.9-14)$
11.02)
19.5)
$0.0001 / 0.001$

Phosphorus day 1*

$\begin{array}{ccccc} & \\ 2.7(0.81) & 3.3(1.15) & 4.6(1.7) & 4.0(1.7) & 0.0001 / 0.001\end{array}$

Phosphorus day 3*

$\begin{array}{lcccc} \\ 3.4(1.2) & 4.6(1.77) & 4.4(1.51) & 4.4(1.7) & 0.0001 / 0.001 \\ 17.71(7.4- & 2.29(0.71- & 2.72(0.67- & 2.5(0.79- & <0.0001 /< \\ 28.6) & 6.84) & 5.3) & 7.2) & 0.0001\end{array}$

CRP/albumin ratio day

$3 * *$
$8.67(2.94-$
$1.99(0.52-$
4.54 (1.87-
$2.4(0.66-$
$<$
19.09)
4.57)
7.69)
$6.42)$
$0.0001 / 0.037$

Oxygenation index day

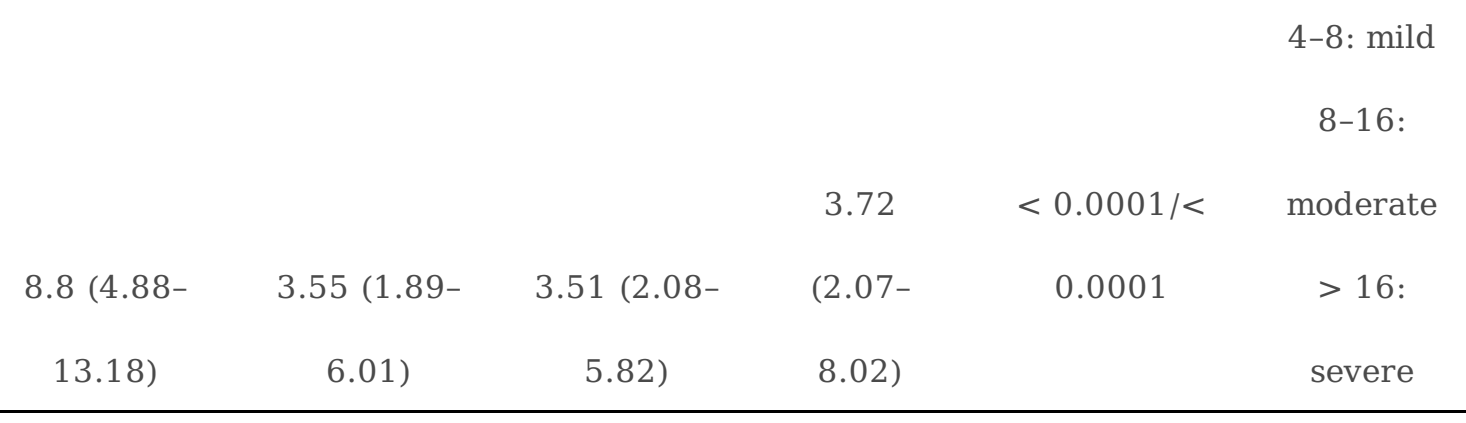


*mean (SD); **median (IQR); *** p value without and with Bonferroni adjustment. Peep: Positive end expiratory pressure. CRP: C-reactive protein.

In general, patients diagnosed with MIS-C were associated with greater need for intensive support and worse clinical outcomes, compared to patients with severe and/or critical COVID-19. Multivariate analysis identified exposure time $>21$ days and $\mathrm{Ol}$ at admission up to 8 as independent risk factors for the presence of critical SARS-CoV-2 infection. Prothrombin time (TP) levels $>15 \mathrm{~s}$ at admission were associated with a higher risk of death, while underweight was associated with longer permanence in the IMV and at the hospital, as shown in Table 3.

Table 3. Multivariate analysis 


\begin{tabular}{|c|c|c|c|}
\hline & OR & CI $95 \%$ & $p$-value \\
\hline \multicolumn{4}{|c|}{ Severe or critical clinic form of SARS-CoV-2 infection } \\
\hline Exposure time more than 21 days & 2.1 & $1.4-3.25$ & 0.001 \\
\hline Oxygen index at admission up to 8 & 1.4 & $1.1-1.8$ & 0.005 \\
\hline \multicolumn{4}{|r|}{ Death } \\
\hline Prothrombin time in seconds day 1 longer than 15" & 1.4 & $1.1-1.7$ & 0.001 \\
\hline \multicolumn{4}{|c|}{ Length of stay at PICU up to 7 days* } \\
\hline Ventilator associated pneumonia & 1.25 & $1.1-1.5$ & 0.005 \\
\hline \multicolumn{4}{|c|}{ Length of stay at the hospital up to 7 days* } \\
\hline Male & 10.5 & $1.8-62.4$ & 0.01 \\
\hline Under weight & 10.9 & $1.9-63.1$ & 0.007 \\
\hline \multicolumn{4}{|c|}{ Ventilator-free days at day $28^{*}$} \\
\hline Length of stay in PICU up to 7 days & 1.1 & $1.1-1.2$ & 0.026 \\
\hline Ventilator associated pneumonia & 16.3 & $1.2-22.4$ & 0.043 \\
\hline Phosphorus $<3 \mathrm{mg} / \mathrm{dL}$ & 6.1 & $1.1-33.0$ & 0.035 \\
\hline \multicolumn{4}{|c|}{ Invasive mechanical ventilation time up to five* } \\
\hline Partial pressure of carbon dioxide $\left(\mathrm{pCO}_{2}\right)$ up to $45 \mathrm{mmHg}$ on day 3 & 1.0 & $0.96-1.99$ & 0.041 \\
\hline Underweight IMV & 2.6 & $1.15-5.85$ & 0.03 \\
\hline
\end{tabular}

* These cut-off values are based on the $75^{\text {th }}$ percentile of each outcome, a logistic regression forward stepwise procedure. PICU: pediatric intensive care unit.

\section{Discussion}

This prospective multicenter regional study analyzed the clinical spectrum of SARS-CoV-2 infection in hospitalized children, including acute infections and MIS-C. The aim of this study was to evaluate the factors associated with severe clinical evolution, as well as the short-term clinical outcomes, in the first year of the pandemic, in a scenario of limited resources, and to add new knowledge about the COVID-19 presentation that will be useful in the prevention and control of the eventual third wave of the epidemic. 
Few previous studies have evaluated the factors associated with poor outcomes in pediatric COVID-19 and MIS-C [21-26].

Several epidemiological and clinical similarities were identified between this study and others [1-3, 27$30]$, with an emphasis on the predominance of males [3, 4, 30], individuals of mixed race [5, 31], clinical admissions [6, 32], presence of comorbidities [7, 33], pronounced gastrointestinal and skin manifestations [27, 29, 30], high demand for vasoactive drugs [26, 31], as well as the presence of circulatory shock (mainly cardiogenic) [32,33], presence of ground-glass pneumonia [34, 35], long hospital stay and PICU, and need for invasive ventilatory support [2-6, 36].

It has been hypothesized that the findings described above may be related to a myriad of factors, including genotypic/phenotypic characteristics and unregulated host immune responses, as well as economic and geographical peculiarities, which may limit early access to health services in a health-care limited setting $[26,37-41]$.

Another relevant aspect for the divergences evidenced in countries with low per capita income and/or with peculiar socioeconomic and cultural characteristics is the increased likelihood of neglecting community illnesses. This has a direct and indirect impact on the clinical expression of pathologies, as well as on preventive and curative care strategies. Therefore, studies focused on this epidemiological niche are of great value in the context of deconstructing this reality [42-44].

It is noteworthy that in this study, lymphopenia, OI, SIG and CRP/albumin ratio, and the occurrence of blood disorders were associated with the presence of severe MIS-C. Interestingly, OI, SIG, and $\mathrm{CRP} / a$ lbumin ratio are used to assess hypoxemia, tissue perfusion, and acute phase inflammatory proteins, respectively, while lymphopenia is related to the maturity and functionality of the immune system, both of which can lead to endothelial damage and, consequently, coagulation disorders, all of which determine an imbalance between organic metabolic supply and demand. In addition, an unregulated immune response may be related to unfavorable outcomes.

It is noteworthy that VAP and underweight in this sample were relevant in the independent association with short-term outcomes both in relation to the length of hospital stay and PICU, as well as prolonged duration on IMV and shorter IMV-free days. These findings are not in line with most studies of MIS-C, in which obesity related to the chronic inflammatory process is a hypothetical predisponent to explain the emergence of a cytokine storm [44-48].

In the current study, the overall mortality in patients with MIS-C was higher compared to other studies, and the association of cardiac complications and the need for mechanical ventilation occurred in both groups (G1 and G2), but were more common in post-acute patients, who were also more likely to receive intravenous steroids and immunoglobulins. Other studies reported a similar finding, with the use of human immunoglobulin in $77 \%$ of the SIM-P cases, the use of corticosteroids in $49 \%$, and the use of ECMO in $9 \%$ of the cases $[1-3,27,43,44]$. 
One in ten deaths among children younger than 5 years in low-income and middle-income countries is attributable to severe malnutrition because wasted children are at increased risk of mortality from infectious diseases. Disruptions resulting from the COVID-19 pandemic are expected to continue to exacerbate these scenarios $[40,41,43,48]$. Therefore, this well-known association between mortality, malnutrition, and greater severity of infectious processes could reinforce the explanation of the high mortality rates associated with the current socioeconomic situation of the pandemic in both waves, which have caused damage to the global community, especially to Brazil, where economic, political, and social strategies aimed at coping with COVID-19 are extremely fragile.

It is also emphasized that in services with better health assistance resources, cardiopulmonary assistance, invasive hemodynamic monitoring such as ECMO, and continuous monitoring of hemodynamic variables was offered; however, such technological resources are not available in our service, and in addition to the conditions of bad accessibility to health services in the Amazon region as well as the previously described economic factors make the prognosis worse $[3-6,40,41]$.

\section{Strengths And Limitations}

There are some limitations in our study. First, the limited sample size; second, children were classified using a severity classification that has been previously applied to other pediatric cohorts, which is designed primarily for respiratory symptoms and lung involvement; and finally, the population is based on hospitalized children, which can lead to more severe forms of SARS-CoV-2 infection and may explain the higher frequency of viral pneumonia among the severe phenotypes, but not among patients requiring ICU admission. Moreover, multiple variants of the virus are recognized; however, as viral genotypic determination was not performed in this study, it would be speculative to suggest such cause and effect at this point.

Therefore, in the present study, the subset of critical patients not only included patients with respiratory failure, but also with other potentially fatal conditions. Consequently, in addition to reporting the clinical characteristics, risk factors, and outcomes of COVID-19 in children, this dataset provides a unique opportunity to objectively monitor the emergence and progression of another kind of multisystemic inflammatory syndrome in Brazil, which was the center of the second wave, while minimizing memory bias.

\section{Conclusions}

In our cohort, being less than 24 months old, male, with signs or symptoms of lower respiratory tract infection, presence of a pre-existing medical condition, cardiac involvement, and certain abnormal laboratories were associated with a greater likelihood of requiring PICU admission. Moreover, a significant proportion of these patients required ICU support, often including mechanical ventilation with high doses of vasoactive drugs. Our results also show that most children who are intubated due to respiratory failure 
require prolonged ventilation, usually for one week or more. Coagulation disturbs and underweight are associated with higher mortality and length of stay in the PICU and hospital, respectively.

To the best of our knowledge, this is the first observational study to examine the relative risk of severe COVID-19 and associated mortality among children in Brazil. This study is one of the few in which data from laboratory confirmed patients with COVID-19 were collected prospectively and during admission.

In the Brazilian Amazon, we identified a cluster of more severe forms of MIS-C, and promptly share these results as an urgent public health research priority. Multisystem inflammatory syndrome is a new pediatric disease that is dangerous and potentially lethal. With prompt recognition and medical attention, most children will survive, but the long-term outcomes of this condition are presently unknown.

\section{Abbreviations}

Coronavirus disease (COVID-19)

Multisystem inflammatory syndrome in children (MIS- C)

Pediatric intensive care unit (PICU)

Fundação Santa Casa de Misericórdia do Pará (FSCMPA)

Fundação Hospital das Clínicas Gaspar Viana (FHCGV)

Hospital e Pronto Socorro municipal Mário Pinotti (HPSMMP)

World Health Organization (WHO)

Reverse transcriptase polymerase chain reaction (RT-PCR)

Acute respiratory distress syndrome (ARDS)

Multiple organ dysfunction syndrome (MODS)

Central Laboratory of the State of Pará (LACEN-PA)

Invasive mechanical ventilation (IMV)

Ventilator-associated pneumonia (VAP)

Body mass index (BMI)

Standard deviation (SD)

Interquartile range (IQR) 
Confidence interval (Cl)

Shock syndrome Kawasaki disease (SSKD)

oxygen index (OI)

Prothrombin time (TP)

\section{Declarations}

\section{Ethics approval and consent to participate}

The study was approved by the institutional review board of the coordinating center (the other centers were co-participants). The parents or guardians of the children, or, when applicable, the children themselves, provided written informed consent before being included in the study. Besides, confidentiality was maintained by keeping privacy at all levels of the study. The study was conducted in accordance with the Declaration of Helsinki. The study was approved by the Research Ethics Committee of FSCMPA under number 0361/2017, opinion $n^{\circ} 4.060 .894$, CAAE 31513320.0.0000.5171

\section{Consent for publication}

It is not applicable.

\section{Availability of data and materials}

All the datasets during and/or analyzed during the current study are available from the corresponding author on reasonable request.

\section{Competing interests}

All authors declare that they have no competing interest final content of the manuscript.

\section{Funding}

This study had no financial support.

\section{Authors' contributions}

ECFF, MTT, and GC designed research, conceptualized the study, analysed the data and wrote the manuscript. JPP, MCAJ, MLFMFM, SCDS and PBC assisted with the concept, interpretation of data and reviewed the manuscript. MJCPJ, LMPN, DCAP, VTSS, AHOP, MCBA conducted data collection, interpretation of data, review and editing. All authors have read, reviewed and approved the manuscript.

\section{Acknowledgments}


First of all, we are glad to thank Fundação Santa Casa de Misericórdia do Pará for giving us this chance to conduct this research. Our special thanks go to all the children, parents, and participated PICU.

\section{References}

1. Tsankov BK, Allaire JM, Irvine MA, Lopez AA, Sauvé LJ, Vallance BA, et al. Severe COVID-19 Infection and Pediatric Comorbidities: A Systematic Review and Meta-Analysis. Int $\mathrm{J}$ Infect Dis. 2021;103:246-56.

2. Hoang A, Chorath K, Moreira A, Evans M, Burmeister-Morton F, Burmeister F, et al. COVID-19 in 7780 pediatric patients: A systematic review. EClinicalmedicine. 2020 Jun 26;24:100433. doi: 10.1016/j.eclinm.2020.100433. PMID: 32766542; PMCID: PMC7318942.

3. Kaushik AMD, Gupta SMD, Sood MMD, Sharma SMD, Verma SMD. A systematic review of multisystem inflammatory syndrome in children associated With SARS-CoV-2 infection. Pediatr Infect Dis J. November 2020 -;39:e340-6 -. Issue 11-p e340-e346 doi: 10.1097/INF.0000000000002888.

4. Chao JY, Derespina KR, Herold BC, Goldman DL, Aldrich M, Weingarten J, et al. Clinical characteristics and outcomes of hospitalized and critically ill children and adolescents with coronavirus disease 2019 at a tertiary care medical center in New York City. J Pediatr. 2020 Aug;223:14-19.e2. doi: 10.1016/j.jpeds.2020.05.006. Epub 2020 May 11. PMID: 32407719; PMCID: PMC7212947.

5. Rodriguez-Gonzalez M, Castellano-Martinez A, Cascales-Poyatos HM, Perez-Reviriego AA. Cardiovascular impact of COVID-19 with a focus on children: A systematic review. World J Clin Cases. 2020 Nov 6;8(21):5250-83. doi: 10.12998/wjcc.v8.i21.5250. PMID: 33269260; PMCID: PMC7674714.

6. Pereira MFB, Litvinov N, Farhat SCL, Eisencraft AP, Gibelli MABC, Carvalho WB, et al. Severe clinical spectrum with high mortality in pediatric patients with COVID-19 and multisystem inflammatory syndrome. Clinics (Sao Paulo). 2020;75:e2209. doi: 10.6061/clinics/2020/e2209. Epub 2020 Aug 19. PMID: 32844958; PMCID: PMC7426591.

7. Prata-Barbosa A, Lima-Setta F, Santos GRd, Lanziotti VS, de Castro REV, de Souza DC, et al.. Pediatric patients with COVID-19 admitted to intensive care units in Brazil: a prospective multicenter study. Jornal de Pediatria. 2020;96:582-92.

8. de Farias ECF, Pedro Piva J, de Mello MLFMF, do Nascimento LMPP, Costa CC, Machado MMM, et al.. Multisystem Inflammatory Syndrome associated with Coronavirus Disease in Children: A Multicentered Study in Belém, Pará, Brazil. Pediatr Infect Dis J. 2020;39:e374-6.

9. World Health Organization. [homepage on the Internet]. Geneva: WHO, 19; 2020. Multisystem Inflammatory Syndrome in Children and Adolescents Temporally Related to COVID. https://www.who.int/news-room/commentaries/detail/multisystem-inflammatory-syndrome-inchildren-and-adolescents-with-covid-19. Accessed 2020 December 7. 
10. The Society of Pediatrics CMA. the Editorial Board CJ of P. Recommendations for the diagnosis, prevention and control of the 2019 novel coronavirus infection in children (first interim edition). Chin J Pediatr. 2020;58(0):E004.

11. Proulx F, Gauthier M, Nadeau D, Lacroix J, Farrell CA. Timing and predictors of death in pediatric patients with multiple organ system failure. Crit Care Med. 1994;22(6):1025-31 doi:

10.1097/00003246-199406000-00023.

12. Feudtner C, Feinstein JA, Zhong W, Hall M, Dai D. Pediatric complex chronic conditions classification system version 2: updated for ICD-10 and complex medical technology dependence and transplantation. BMC Pediatr. 2014;14:199. doi.org/10.1186/1471-2431-14-199.

13. Pollack MM, Holubkov R, Funai T, Dean JM, Berger JT, Wessel DL, et al. The pediatric risk of mortality score. Pediatr Crit Care Med. 2016;17(1):2-9.

14. Straney L, Clements A, Parslow RC, Pearson G, Shann F, Alexander J, et al. Paediatric index of mortality 3: an updated model for predicting mortality in pediatric intensive care. Pediatr Crit Care Med. 2013;14(7):673-81.

15. Leteurtre S, Duhamel A, Salleron J, Grandbastien B, Lacroix J, Leclerc F, et al. PELOD-2: an update of the PEdiatric logistic organ dysfunction score. Crit Care Med. 2013;41(7):1761-73.

16. Béduneau G, Pham T, Schortgen F, Piquilloud L, Zogheib E, Jonas M, et al. Epidemiology of Weaning Outcome according to a New Definition. The WIND Study. Am J Respir Crit Care Med. 2017;195:77283.

17. Mourani PM, Sontag MK. Ventilator-associated pneumonia in critically ill children: A new paradigm. Pediatr Clin North Am. 2017;64:1039-56.

18. Schoenfeld DA, Bernard GR, ARDS Network. Statistical evaluation of ventilator-free days as an efficacy measure in clinical trials of treatments for acute respiratory distress syndrome. Crit Care Med. 2002;30:1772-7. doi: 10.1097/00003246-200208000-00016.

19. Pediatric Acute Lung Injury Consensus Conference Group. Pediatric acute respiratory distress syndrome: consensus recommendations from the Pediatric Acute Lung Injury Consensus Conference. Pediatr Crit Care Med. 2015;16(5):428-39. doi: 10.1097/PCC.0000000000000350.

20. WHO Multicentre Growth Reference Study Group. WHO Child Growth Standards: methods and development. Length/height-forage, weightfor-age, weight-for-length, weight-for-height and body mass index-for age: methods and development.

http://www.who.int/childgrowth/standards/technical_report/en/index.html. Acess November. 2020;20.

21. Carter MJ, Shankar-Hari M, Tibby SM. Paediatric inflammatory multisystem syndrome temporallyassociated with SARS-CoV-2 infection: an overview. Intensive Care Med. 2021;47(1):90-3. https://doi.org/10.1007/s00134-020-06273-2.

22. Fernández-Sarmiento J, De Souza D, Jabornisky R, Gonzalez GA, Arias López MDP, Palacio G. Paediatric inflammatory multisystem syndrome temporally associated with COVID-19 (PIMS-TS): a narrative review and the viewpoint of the Latin American Society of Pediatric Intensive Care (SLACIP) 
Sepsis Committee. BMJ Paediatr Open. 2021;5(1):e000894. https://doi.org/10.1136/bmjpo-2020000894.

23. Riphagen S, Gomez X, Gonzalez-Martinez C, Wilkinson N, Theocharis P. Hyperinflammatory shock in children during COVID-19 pandemic. Lancet. 2020;395: 1607-1608. doi: 10.1016/S01406736(20)31094-

24. Whittaker E, Bamford A, Kenny J, Kaforou M, Jones CE, Shah P, et al. Clinical characteristics of 58 children with a pediatric inflammatory multisystem syndrome temporally associated with SARS-CoV2. JAMA. 2020;324(3):259-69. doi:10.1001/jama.2020.10369.

25. DeBiasi RL, Song X, Delaney M, Bell M, Smith K, Pershad J, et al. Severe coronavirus Disease-2019 in children and young adults in the Washington, DC, metropolitan region. J Pediatr. 2020;223:199203.e1. 10.1016/j.jpeds.2020.05.007.

26. Hoang A, Chorath K, Moreira A, Evans M, Burmeister-Morton F, Burmeister F, et al. COVID-19 in 7780 pediatric patients: a systematic review. E Clinical Medicine 2020. EClinicalMedicine,24:100433. 10.1016/j.eclinm.2020.100433.

27. Miller J, Cantor A, Zachariah P, Ahn D, Martinez M, Margolis KG. Gastrointestinal symptoms as a major presentation component of a novel multisystem inflammatory syndrome in children that is related to Coronavirus Disease 2019: A Single Center experience of 44 cases. Gastroenterology. 2020;159, issue 4:1571-1574.e2, https://doi.org/10.1053/j.gastro.2020.05.079.

https://www.sciencedirect.com/science/article/pii/S0016508520347533.

28. Larenas-Linnemann D, Luna-Pech J, Navarrete-Rodríguez EM, Rodríguez-Pérez N, Arias-Cruz A, Blandón-Vijil MV, et al. Cutaneous manifestations related to COVID-19 immune dysregulation in the Pediatric Age Group. Curr Allergy Asthma Rep. 2021;21:13. https://doi.org/10.1007/s11882-02000986-6.

29. Giacomet V, Barcellini L, Stracuzzi M, Longoni E, Folgori L, Leone A, et al. Gastrointestinal Symptoms in Severe COVID-19 Children. Pediatr Infect Dis J. 2020 Oct;39(10):e317-20. doi: 10.1097/INF.0000000000002843. PMID: 32932333.

30. Pignatelli R, Antona CV, Rivera IR, Zenteno PA, Acosta YT, Huertas-Quiñones M, et al. Pediatric multisystem SARS COV2 with versus without cardiac involvement: a multicenter study from Latin America. Eur J Pediatr. 2021;180:2879-88. https://doi.org/10.1007/s00431-021-04052-9.

31. Grimaud M, Starck J, Levy M, Marais C, Chareyre J, Khraiche D, et al. Acute myocarditis and multisystem inflammatory emerging disease following SARS-CoV-2 infection in critically ill children. Ann Intensive Care. 2020;10:69. 10.1186/s13613-020-00690-8.

32. Belhadjer Z, Méot M, Bajolle F, Khraiche D, Legendre A, Abakka S, et al. Acute heart failure in multisystem inflammatory syndrome in children in the context of global SARS-CoV-2 pandemic. Circulation. 2020;142:429-36. 10.1161/CIRCULATIONAHA.120.048360.

33. Rostad BS, Shah JH, Rostad CA, Jaggi P, Richer EJ, Linam LE, et al. Chest radiograph features of multisystem inflammatory syndrome in children (MIS-C) compared to pediatric COVID-19. Pediatr 
Radiol. 2021 Feb;51(2):231-8. doi: 10.1007/s00247-020-04921-9. Epub 2021 Jan 6. PMID: 33404786; PMCID: PMC7785920.

34. Biko DM, Ramirez-Suarez KI, Barrera CA, Banerjee A, Matsubara D, Kaplan SL, et al. Imaging of children with COVID-19: experience from a tertiary Children's Hospital in The United States. Pediatr Radiol. 2021 Feb;51(2):239-47. doi: 10.1007/s00247-020-04830-x. Epub 2020 Sep 18. PMID: 32945888; PMCID: PMC7498743.

35. Mistry R, Scanlon N, Hibberd J, Fuller F. Early recognition of PIMS-TS: a single centre retrospective review. BMJ Paediatr Open. 2021;5(1):e001011. https://doi.org/10.1136/bmjpo-2020-001011.

36. Davies P. Addressing fundamental questions on MIS-C. Lancet Child Adolesc Health. 2021 Mar 9;5:310-1. doi: 10.1016/S2352-4642(21)00059-6. Epub ahead of print. PMID: 33711292.

37. Anderson G, Carbone A, Mazzoccoli G. Aryl hydrocarbon receptor role in Co-ordinating SARS-CoV-2 entry and symptomatology: linking cytotoxicity changes in COVID-19 and cancers; modulation by racial discrimination stress. Biology. 2020;9(9):249. https://doi.org/10.3390/biology9090249.

38. Hoste L, Van Paemel R, Haerynck F. Multisystem inflammatory syndrome in children related to COVID-19: a systematic review. Eur J Pediatr. 2021 Feb 18;180:2019-34. doi: 10.1007/s00431-02103993-5. Epub ahead of print. PMID: 33599835; PMCID: PMC7890544.

39. Esposito S, Principi N. Multisystem inflammatory syndrome in children related to SARS-CoV-2. Paediatr Drugs. 2021 Mar;23(2):119-29. doi: 10.1007/s40272-020-00435-x. Epub 2021 Jan 22. PMID: 33479801; PMCID: PMC7819738.

40. Fanos V, Pintus R, Pintus MC, Mussap M, Marcialis MA. Seven secrets of COVID-19: fever, ACE2 receptors, gut-lung axis, metabolomics, microbiomics, probiotics, diet. J Pediatr Neonatal Individ Med (JPNIM). 2021;10(1):e100145. https://doi.org/10.7363/100145.

41. García-Salido A, Leoz-Gordillo I, Martínez de Azagra-Garde A, Nieto-Moro M, Iglesias-Bouzas MI, García-Teresa MÁ, et al. Children in critical care due to severe acute respiratory syndrome coronavirus 2 infection: experience in a Spanish Hospital. Pediatr Crit Care Med. 2020 Aug;21(8):e576-80. doi: 10.1097/PCC.0000000000002475. PMID: 32459790; PMCID: PMC7255394.

42. Zachariah P, Johnson CL, Halabi KC, Ahn D, Sen Al, Fischer A, et al. Epidemiology, clinical features, and disease severity in patients with coronavirus disease 2019 (COVID-19) in a Children's Hospital in New York City, New York. JAMA Pediatr. 2020;174(10):e202430.

43. Götzinger F, Santiago-García B, Noguera-Julián A, Lanaspa M, Lancella L, Calò Carducci FI, et al. COVID-19 in children and adolescents in Europe: a multinational, multicentre cohort study. Lancet Child Adolesc Health. 2020;4(9):653-61.

44. Fernandes DM, Oliveira CR, Guerguis S, Eisenberg R, Choi J, Kim M, et al. Severe Acute Respiratory Syndrome Coronavirus 2 Clinical Syndromes and Predictors of Disease Severity in Hospitalized Children and Youth [published online ahead of print November 13, 2020]. J Pediatr. 2021;230:2331.e10 doi: 10.1016/j.jpeds.2020.11.016.

45. Ouldali N, Yang DD, Madhi F, Levy M, Gaschignard J, Craiu I, et al. Factors associated with Severe SARS-CoV-2 Infection. Pediatrics. 2021 Mar;147(3):e2020023432. doi: 10.1542/peds.2020-023432. 
Epub 2020 Dec 15. PMID: 33323493.

46. Horton R. Offline: global health's indifference to poverty must end. Lancet. $2019 \mathrm{Jul}$ 27;394(10195):286. doi: 10.1016/S0140-6736(19)31710-6.

47. Greenberg MR. Insidious trends and social/environmental justice: public health's challenge for responding to hazard events. Am J Public Health. 2014;104(10):1802-4. https://doi.org/10.2105/AJPH.2014.302162.

48. Black RE, Victora CG, Walker SP, Bhutta ZA, Christian P, de Onis M, et al. Maternal and child undernutrition and overweight in low-income and middle-income countries. Lancet. 2013;382:42751.

\section{Figures}

\begin{tabular}{|c|c|}
\hline $\begin{array}{l}528 \text { patients admitted at three PICUs:* } \\
\text { Assessed for eligibility }(\mathrm{n}=287) \\
\text { No intensive care support }(\mathrm{n}=163) \\
\text { Incomplete data }(\mathrm{n}=19)\end{array}$ & \\
\hline Refusal $(\mathrm{n}=59)$ & $\begin{array}{l}\text { Group I }(\mathrm{n}=55) \\
\text { MIS-C group }\end{array}$ \\
\hline $\begin{array}{c}\text { Included }(\mathrm{n}=228) \\
\text { Excluded }(\mathrm{n}=59) \text { : } \\
\text { Incomplete or unknown vaccination status }(\mathrm{n}=20) \\
\text { Immunocompromised }(\mathrm{n}=27)\end{array}$ & $\begin{array}{l}\text { Group II }(\mathrm{n}=96) \\
\text { acute COVID-19 group }\end{array}$ \\
\hline End of life decision $(n=12)$ & $\begin{array}{c}\text { Group III }(\mathrm{n}=77) \\
\text { MODS with epidemiological link } \\
\text { group }\end{array}$ \\
\hline
\end{tabular}

\section{Figure 1}

Flowchart describing the study design and selection of participants *PICU: Pediatric intensive care unit. 